\title{
The Dimensions of Language and Thought in the Vedic Literature
}

\author{
Sabindra Raj Bhandari \\ Tribhuvan University, Kathmandu, P. N. Campus, Pokhara, Nepal
}

\begin{abstract}
The present article explores the interrelationships between language and thought in the literature of the Vedic Canon. Whether language shapes thoughts or vice versa has remained a topic pregnant with perpetual discussions, interpretations, and explanations since the beginning of human civilization. Throughout the multiple crossroads of the development in the intellectual tradition, the dimensions of language and thought attracted many scholars and linguists. However, linguists like Edward Sapir and Benjamin L. Whorf in the twentieth century have systematically interpreted and analyzed the language-thought dimensions. Whorf postulated that language shapes thoughts while Sapir projected that language is in the grip of thought. The literature of the Vedic Canon has also logically and systematically projected the multiple dimensional, but agglutinative relationships between language and thought. The hymns of the Rig Veda, myths from Brahmanas, and the lore from Upanishads unravel, interpret, and enrich the language-thought interconnection in such a way that the Vedic literature remains as the classical version of Sapir-Whorf hypothesis written in Sanskrit. In this regard, the Vedic literature and Sapir-Whorf hypothesis play the same tune of music in different lyres. The present paper attempts to reveal this point of unity in diversity between the two seemingly diverse schools of thoughts - classical Vedic literature and modern linguistic theory of Sapir-Whorf hypothesis. Being the qualitative research, this paper explores, interprets, and correlates the theoretical concepts, ideas, and phenomena from the Vedic literature and Sapir-Whorf hypothesis.
\end{abstract}

Index Terms - dissect, language, mantra, Sapir-Whorf hypothesis, thought, vedic literature

\section{INTRODUCTION}

The literature of the Vedic canon values the language-thought interrelationship. It also projects that only in this interrelationship the total aspect of reality is expressed. The domain of language becomes so powerful in the Vedic literature that every word assigns itself with the source of reality. This language-thought dimension is also the major quest of Whorfian hypothesis - also called Sapir-Whorf hypothesis and Whorfianism-postulated by Edward Sapir and notably by Benjamin Lee Whorf in the mid-twentieth century. In essence, both the Vedic literature and Sapir-Whorf hypothesis contend that language shapes, influences, affects, magnifies, and even confines the domain of thought. Hence, it remains to be explored how the Vedic literature projects the language-thought dimensions postulated mainly by linguists like Edward Sapir and Benjamin Lee Whorf in our time.

The exact beginning of the Vedic literature is a matter of guesswork as scholars do not have unanimous views about it. Macdonell, Oldenberg, and Muller (2014) explain that on the ground of astronomy, Sanskrit scholars guess the oldest Vedic hymns were composed from $3000 \mathrm{BC}$, while some other speculate that they were composed as far back as 6000 BC. However, with some other evidences the composition of Rig Vedic hymns was not later than thirteenth century BC (p. 12-13). Those beautiful hymns were composed in the Sanskrit. Since the Vedas were revelation, a single author could not have composed them; rather they were divine. So, the Vedas are shruti, direct revelation from the God, carrying the divine truth. There are four Vedas, and they are Rig Veda, Sama Veda, Yajur Veda, and Atharva Veda. Fundamentally, "the word Veda means knowledge" (Hamilton, 2007, p. 20). The Rig Veda is the oldest book of poetry ever written in any languages, and this great book deals with multiple dimensions of knowledge. The knowledge is delivered in divine language known as mantra. Mantra is "Prayer, sacred formula (from the root man - to think), holy word, a Vedic text or verse .... Being a powerful word, it can also have the meaning of spell or incantation" (Panikkar, 1994, p. 882). Therefore, the part of language is given divine power in the Vedic literature. The canon of Vedic literature consists of four categories namely, Samhita (collection of mantras), the Brahmana, the Aranyaka, and the Upanishad. The Samhitas are the earliest mantras, and imply simply the collection of the hymns. The four Vedas are the collection of Samhitas or mantras. Among them, the Rig Veda consists of 10,600 mantras, the Sama Veda is a collection of 1873 mantras, the Yajur Veda has 1975, and the Atharva Veda has 5977 mantras. It is the Rig Veda, which occupies the knowledge of different fields.

The Brahamanas simply give the detail explanation of rituals and sacrificial practices of the Veda. According to Radhakrishnan (2016) the rituals found in the Vedas are developed in Brahmanas into an enlarged system of ceremonies (p. 46). The Aranyakas (forest treatises related to forest dwellers) do not relate with ritual practices, but they present the mystical and philosophical teachings that the Vedas proclaim. The Upanishad represents the culmination of the theoretical and philosophical explanation of Vedic mantras. So, they are called Vedanta, which is known as the "final truth or "end" (anta) of the Vedas" (Zimmer, 2011, p. 606). In this sense, the literature of the Vedic canon is so 
vast. Although the literature had come into its crux earlier than Christ, the literature of this canon consists of genuine truth about different aspects of this world. Therefore, the Veda remains still a matter of exploration, explanation, and interpretation with the new perspectives.

\section{REVIEW OF THE RELATED LITERATURE}

The language of the Vedic literature crystallizes the basic concept of language-thought interconnection. The Vedic literature employs Sanskrit language, the mother language of entire Indo-European languages. The whole literature of the Vedic canon is written in Sanskrit. Describing the real essence of Sanskrit Literature, language and its connection with modern linguistics, Frawley (1992) writes:

The Rig Veda is the source book of the Sanskrit language, the oldest most continually used language in the world, containing what is perhaps the largest literature in the world, particularly in the spiritual realm. Sanskrit is one of the most scientific of all languages and the most etymologically consistent. Much of the modern linguistic has developed from the study of Sanskrit. (p. 24)

These lines from Frawley, a Vedic scholar, cherish the multiple dimensions of Sanskrit language, and its relation to the modern linguistics. It also makes the present study justifiable to explore the interrelationship of the tenets and traits in language-thought dimension of Whorfian hypothesis in the Sanskrit literature.

Panini was the first grammarian who systematized grammar of Sanskrit. Whorf (1956) hails Panini and praises the foundation of Sanskrit language. He writes:

So far as the knowledge goes, the science of linguistic was founded, . . . by Panini in India several centuries before Christ. Its earliest form anticipated its most recent one. Panini was highly algebraic, i.e., pattern symbolic, in treatment; he used formulas in very modern way for expressing the obligatory patterns of Sanskrit ... . Modern scientific linguistic dates from the discovery of Panini by the Western World in the early nineteenth century. (p. 232)

It is obvious from the above description that the linguistic interpretation of language by the modern linguists must have maintained some connections with the Sanskrit language and literature where the linguistic interpretation has been perfectly implemented. In this essence too, the Whorfian hypothesis must make the revelation in its own way in the Sanskrit literature. And this aspect needs to be explored thematically in the Sanskrit language.

If the Sanskrit language is scientific and practical, it must make its connection with the practical world too. Showing the relationship between Sanskrit language and knowledge, Hamilton (2001) clarifies that "... the rules of the language of the Veda, the way that language was operational in the world maintained by the sacrificial was also established; and that the relationship between language and knowledge of that world could be articulated" (p. 60). Thus, the languagethought relationship has been noticed clearly in the very foundation of the Sanskrit literature because literature conveys the thoughts and knowledge to the world.

The Sanskrit literature reflects language-thought relationship because of its unique language form which is called mantra. This is the most crucial aspect of the Vedic literature. Frawley (1992) beautifully defines the pattern of language of the Veda as mantra:

Mantra is the original form of all language, the original language from which all others derive. Mantric language ... is language in which sound and meaning correspond. It is like poetry where in sound of words reflects their meaning and aids in its manifestation. More than this, it is a science of sound where in the meaning and force of all sound is known and developed towards mergence in the Divine word. (p. 43)

The power of the Vedic language has been clearly stated in the given lines. The word as mantra represents the entire dimensions of the language in the Veda, and establishes the communion between the phenomenal and transcendental world i.e. between the individual consciousness and the cosmic consciousness.

This greatness of the Sanskrit language and the literature of Vedic canon provide not only the mundane process of naming objects, but the power of divinity as well. To clarify it, Muller was right to say; "I spend my happiest hours in reading Vedantic books. They are like to me the light of the morning . . . . I maintain that to everybody who cares for himself, for his ancestors, for his intellectual development, a study of Vedic literature is indeed indispensable" (as cited in Goldberg, 2010, p. 29). Therefore, the study of the Vedic literature is must, and this present article explores some aspects of the Vedic literature with the language-thought dimensions of Sapir-Whorf hypothesis which is essentially important.

\section{STATEMENT OF THE PROBLEM}

Scholars have defined, interpreted, and explored the different aspects of the Vedic literature. However, the languagethought dimension, which is an underlying issue in the literature of Vedic cannon, invites an exploration with a touch of novelty. Thus, if the Vedic literature values the word and language as the ultimate path to realize and express truth and knowledge, it obviously needs a systematic analysis and interpretation from the perspective of Sapir-Whorf hypothesis. Therefore, this article attempts to answer the following questions: What are the fundamentals of the intricate relationship between language and thought? How does the Vedic literature expose the multiple dimensions of language 
and thought? How do the Rig Vedic hymns, myths from the Brahmanas, and Upanishadic lore project the fundamental aspects of Sapir-Whorf hypothesis?

\section{OBJECTIVES}

This article intends to reveal how the classical Vedic literature exposes idea and concept of the language and linguistic explanation that have been developed in modern time. It also aims to bridge between the developments of thoughts in the classical literature of the Vedic canon composed in the Sanskrit with the modern linguistic perspective of Sapir-Whorf hypothesis related to the dimensions of language and thought.

\section{Methodology}

The present article has applied the qualitative approach of inquiry because this approach "is a means for exploring and understanding the meaning individuals or groups ascribe to a social or human problems" (Cresswell, 2011, p. 4). This article has also dealt with the understanding and exploring the dimensions of language and thought in the literature of the Vedic canon. So, the main theoretical strategies to analyze the Vedic literature have attracted the concepts and ideas developed by Sapir and Whorf. It has only concerned with the theoretical aspects of language-thought relationship explained by Sapir and Whorf and their correlation and projection in the Vedic hymns, Brahmanas and the Upanishadic lore. Thus, they have become the source of primary concepts, ideas and phenomena to analyze the Sapir-Whorf hypothesis. The criticisms, reviewed and the other related information have been considered as the secondary sources of concepts. Since, the article has only explored with the theoretical and conceptual dimension of Sapir-Whorf hypothesis in the canon of Vedic literature, this research paper has not noticed other aspects in details.

In the subsequent sections, it would be really interesting and mesmerizing to see how the language of the Vedic literature expresses the language-thought interconnection to enrich the hypothesis of Sapir and Whorf.

\section{LANGUAGE-THOUGHT INTERRELATIONSHIP: SAPIR-WHORF HYPOTHESIS}

Language is a peculiar aspect of human behavior. This faculty distinguishes human from other animals. The fundamental attribute of human language is quite unique and universal, so it is around us in our day to day affairs "in speech, writing, sign language, or simply in our minds as we dream, remember a conversation, or quietly think out a problem. It is a vehicle of power, a means by which we control, create, and preserve" (Traugott \& Pratt, 1980, p. 1). It clarifies that language is what makes us feel, move and correlate our ideas with the events of the world, which is possible only with the amalgamation of language with the thought. More than amalgamation, there is also a tendency to presuppose whether language determines thought or language affects and influences thought. This issue foregrounds after the ideas and concepts delivered by Edward Sapir. However, it is Benjamin Lee Whorf who projected this aspect of the dominance of language in thought process. His theory is popularly known as Whorfian Hypothesis. Whorf worked and researched on the language of Hopi people, who live in the northeastern Arizona of the United States. With his great efforts, he concluded that language and thought are intricately linked with culture. Because of the differences in language, the thought process, cultural rites, customs and even the nature of people differ. This theory propounded by Whorf is called "linguistic relative principle" which Whorf (1956) defines thus:

These automatic, involuntary patterns of language not the same for all men but are specific for each language and constitute the formalized side of the language, or its "grammar" _ . . . .

From this fact proceeds what I have called the "linguistic relatively principle," which means, in informal terms, that users of markedly different grammars are pointed by their grammars toward different types of observations and different evaluations of externally similar acts of observations, and hence are not equivalent as observers but must arrive as somewhat different views of the world .... Thus the world view of modern science arises by higher specialization of the basic grammar of the Western Indo-European language. (p. 221)

Whorf's conclusion clearly states that language shapes thought. Different observers possess different perceptions about nature because of the differences in the languages. Seuren (2013) is right while explaining Whorfian hypothesis and its relation with the society and the domain of culture. He views that the supporting arguments of the Whorfian hypothesis consist in revealing that linguistic variation and linguistic change correlate with culturally and socially shared conceptual variation (p. 82). The point is that in linguistic-relative principle encompasses the social, cultural, and natural aspects as well.

Our thinking process enlarges with the level of cognition. The more naming process gives names to the things around, the more thought is accumulated in space time dimension. This is a relative process. The situation determines it. This is the reason why the language of Eskimo has more words to describe the patterns and differentiation of the snow than the English people. And English people have much more thoughts and ideas about the technology and science and other fields than those of Eskimo. In this way, the greatest crux of Whorf version comes in this context when he comes to join nature, culture, language and thoughts. Whorf builds up his hypothesis:

It was found that the background linguistic system (in other words, the grammar) of each language is not merely a reproducing instrument for voicing ideas but rather is itself the shaper of ideas, the 
program and guide for the individual's mental activity, for his analysis of impression, . . . . Formulation of ideas is not an independent process, strictly rational in the old sense, but is part of a particular grammar, and differs from slightly to greatly, between different grammars. We dissect nature along lines laid down by our native languages. (pp. 212-13)

This is the key aspect of Whorf which is better known as Whorfian Hypothesis. Fundamental issue of this hypothesis is that the dissection and concept building process of the phenomenal world is possible because "we dissect nature along the lines laid by our language." If this is the reason, then obviously language shapes the thoughts; language is primary and thought is secondary. This proposition means that language-mind influence is one sided. Sometimes, however, this hypothesis is also called Sapir-Whorfian hypothesis which states that the relation between thought and language is two-sided. One influences the other, and because of this sequential chain of influences, the understanding and cognition of ideas about the world is possible. This view of Sapir also makes intricate relation with hypothesis postulated by Whorf.

The hypothesis is conjointly called Sapir-Whorf hypothesis because nature's dissection with language is more than that. Whorf (1956) even opens the floor for both language- thought interactions when he says:

Moreover, the tremendous importance of language cannot, in my opinion, be taken to mean necessarily that nothing is back of it of the nature of what has traditionally been called by "mind." My own studies suggest to me that language, for all its kingly role, is in some sense a superficial embroidery upon deeper process of consciousness, which are necessary before any communication, signaling or symbolism .... (p. 239)

If language is embroidery upon the thoughts, it is clear from this point that the interaction is a two sided process, and this is perpetual. The more chainless interactions between the two, the more colorful ideas and explanations about the nature and this worldly existence emerge. If language is embroidery, the beautiful, frame structure of consciousness that is obviously thought also determines language. However, the word "superficial" does not reflect the idea of less value. Here "superficial" reflects the foundation, a means, a path, which gives the way out. If the body, the form is language; its breath, the inner path may be the thoughts. One depends on the other, and exists because of other.

The Whorfian hypothesis brought a paradigmatic shift in the language learning process, and it changed the dichotomy about the concept of language and ideas. The larger storehouse of vocabulary leads to the attainment of much more perception and ideas. Confinement on language is the confinement in the thoughts. However, one relies on the other. This had a great impact on teaching pedagogy too. Traugott and Pratt (1980) logically explain this connection: If language does in fact determine thought, and if it does primarily through morphology rather than syntax or phonology, then, it was argued, teachers should be able to improve the thought processes of their pupils by teaching certain kinds of words and morphemes, especially grammatical ones (p.107).

This is the way Whorfian hypothesis energized the process of language. This hypothesis as a great theory of language did not only affect teaching pedagogy, but also politics. Language both increases and decreases thought. In this regard, "Another issue in the fifties was whether language could be manipulated for political purposes that people would be totally tyrannized or "brainwashed" by it" (Traugott \& Pratt. 1980, 107). It proves how Whorfian Hypothesis crystallizes the inner essence: language as power, a foundation of thought process.

Before Sapir and Whorf, Humboldt (1896) inspected about language thought relationship. But Sapir and Whorf projected the theory with systematic analysis of semantic and conceptual structure of the language. Their hypothesis states, according to Gentner and Meadow, firstly that language varies according to their semantic partitioning of the world. Secondly, the structure of one's language affects and designs the manner of the perceiver and his or her understanding of the world. This is the main reason speakers of different languages view and perceive the world differently (2003, p. 4). Exactly in the same way, a person from Nepal cognizes and perceives the world shaped by Nepali language and understands it in the forms and structures laid by Nepali language. Even when one has to express the ideas and translate them into another language, still then the main foundation remains Nepali language.

Whorfian Hypothesis has also been criticized after Chomsky delivered his concepts in his Generative Grammar. This grammar focuses on the universality of language. Only in the superficial level languages differ, but in the deep level they all are same. Because of this reason, thoughts of one language could be translated into another. In the science of language, "Chomskian emphasis on universals of grammar, coupled with the view that language is a separate systems form general cognition and with de-emphasis of the semantic arena, discouraged any search for a relation between language and cognition" (as cited in Gentner and Meadow, 2003, p. 5). Chomsky's system only discourages the ideas expressed by Sapir and Whorf, but the linguists like Pinker reject the hypothesis. He is of the view, according to Gentner and Meadow, that Whorf was wrong when he hypothesized that one's language determines how one conceptualizes reality is general. However, Whorf was correct in weaker sense. That is one's language does determine how one must conceptualize reality which one has to talk about it (p. 8). Linguists like Slobin support Whorf's idea of thinking and supporting. It is the language which enables us to perceive the world. If the language is considered as lenses, surely it is contribution of Whorfian hypothesis that introduced this theory of novelty in linguistic. In this regard, linguists like Boroditsky, Schmidt, Philips make the strong argument that language along with its system of grammar has a very pervasive role to view how people think about the world and its objects.

The debate goes on perpetually as in the development of intellectual tradition of any field. Gentner and Meadow 
(2003) beautifully summarize the entire debate providing the summation of language- thought debate:

Whether language has an impact on thought depends, of course, on how we define language and how we define thought. It also depends on what we take to be the criterion for "having an impact on." Language can act as a lens through which we see the world; it can provide us with tools that enlarge our capabilities; it can help us appreciates groupings in the world that we might not have otherwise grasped. (p. 12)

Language is, of course, lens. The clearer and more powerful the lens, the much clearer the scenario it captures becomes. Thus, improving one's command over language enlarges his / her horizon of perception, ideas, and knowledge.

\section{LANGUAGE AND Thought IN WORD: A CONTEXT OF THE VEDIC LITERATURE}

The Vedic literature identifies $v \bar{a} c$ which is equivalent to English "word", and the word at first was found as meaningful unit of language. However, "According to Vedic Revelation, vāc, which was at the beginning, cannot be reduced to a single one of its dimensions, rather it has multiple aspects. To begin with, thought and language are here so intermingled that no separation is possible" (Panikkar, 1994, p. 89). From the very beginning, the Vedic literature always postulates the idea of integration and totality. The belief that the ultimate truth lies not in fragmentation becomes the basic norm of Vedic Revelation. In the way, word $(v \bar{a} c)$ as a form of language was given a great value where all the dimensions of language conglomerated to create a totality. Moreover, the word attained the status of God and the ultimate reality in the entire literature of the Vedic canon. The Taittiriya Brahmana makes this great issue clearer as it speculates: "The Word, imperishable, is the Firstborn of truth, mother of Veda and hub of immortality" (Panikkar, 1994, p. 88). Word as the first foundation of language becomes so powerful in the Vedic literature. It is the mother of Veda, which means knowledge. The proclamation is that the entire knowledge germinates out of the word, the first meaningful foundation of language. The status here given to word as language is even more powerful than done by Sapir and Whorf. Word does not only dissect nature, it leads to immortality.

The Rig Veda, the oldest book of poetry ever written, deals with the philosophy of knowledge and language. The Veda, the source of knowledge, is the revelation by the cosmic power which the Veda supposes to be the God. So the word is not confined within the dimension of human being. That's why; it can rule the entire phenomenal existence of the world. This aspect magnifies Whorfian concept that language influences thought. The word transcends every ephemeral aspect and becomes divine.

Whorfian hypothesis transcends mundane affairs in the literature of the Vedic canon. The word as the basic meaningful unit of language becomes eternal. The hymn seventy one of book X of Rig Veda describes the origin of word and language. It is by the vehicle of language that the knowledge speculated by the seers transmits itself to the world. The hymn speaks:

O Lord of the Holy Word! That was the first

beginning of the Word when the Seers fell to naming each object.

That which was best and purest, deeply hidden

within their hearts, they revealed by the power of their love.

The Seers Fashion the Word by means of their mind,

sitting it as with sieves the corn is shifted.

Thus friends may recognize each other's friendship.

An auspicious seal open their word is set.

Yet certain ones, though seeing, may not see her,

and other ones, though hearing, may not hear her.

But to some the Word reveals herself quite freely,

Like fair-robed bride surrendering to her husband. (Panikkar, 1994, p. 94)

Obviously, it is by the power of language that the seers are able to name the objects. The divine knowledge finds its path when the world is viewed with the lenses of the word. When the language recognizes the mind or their interaction takes place, then everything finds its value. The worldly activities start to become valuable. The magnification of word is essential in this context. The Sapir-Whorf proclamation on language-mind collaboration finds its finest expression in these beautiful mantras of the Veda. After reading these lines, it appears that Whorf, sitting somewhere in the lap of Himalaya, might have composed these verses that have beautifully justified and maintained the agglutinative relationship between thought and language.

The Vedic literature always establishes the celebration in cosmic order, the order between the human and nature. This binding aspect is called Yoga. Derived from the root "yuj", it means "to bind together". Yoga therefore signifies "harnessing or applying oneself to" (Hiriyanna, 2000, 19). More than that in its complete phase it means, " 'merging' or 'uniting': either self| soul (atman) with universal essence (Brahman), . . . soul with God. It can also lie more in the linked concepts of internal 'control', 'harmony', 'order', or of what one might call 'integrity of insight'" (Hamilton, 2007, p. 107). The personal attributes are linked to cosmos. Therefore, human activities are known simply as the phenomenal manifestation of the cosmic order. The names and objects, in this way, also become the reflection of the divinity. These binding concepts of integration are the essence of the literature of the Vedic canon. Whorf also praises 
this yogic concept when he says: "I would like the subtle Eastern ideas of the mantric and yogic use of language" (1946, p.250). The yogic use of language has nothing than to give the divine pattern to the word. The word becomes mantra (formula), bearing some esoteric power. The objects are simply the exoteric forms. The theory of linguistic relativity also brings the idea that thought is accumulated according to the language which is also influenced by cultural pattern. The Vedic culture, in its essence, regards the language as eternal even beyond the creation. The hymn of Rig Veda VII 75, 6 postulates the word as "nitya $v \bar{a} c$, the eternal word" (Panikkar, 1994, p. 92). The concept relates eternity with the language. As such, the language becomes powerful possessing the divine power and becomes mantra in the hymns of Vedic literature. As discussed earlier in the introductory section, mantra derives from the root man, which means (to think). In this way, all Vedic words and the language hold the miraculous power. The word mantra itself means to think. Thus, the Vedic literature sonorously projects the multiple dimensions and their endless cycles of interconnections between thought and language.

The Vedic culture established human-nature relationship. For the maintenance of this cosmic order there was great value of sacrifices. They were addressed to different deities and Gods. To create concept about the Gods and deities, language must be mystical and insightful. Consequently, Macdonell, Oldenberg, and Muller (2014) rightly conclude that Vedic literature contains much genuine poetry. As the Gods are mostly connected with natural phenomena, the praises addressed to them give birth to remarkable and noble imagery (p. 28). Since the culture is to maintain the integration, the language also attains the value of mantra, possessing the power-the power of divinity. This idea is beautifully invoked in some mantras from book one, hymn 164, verses 34, 35, and 37 of the Rig Veda:

I ask thee of the earth's extremest limit, where is center of the world, I ask thee.

I ask thee of Stallion's seed prolific, I ask of highest where speech abideth.

This alter is the earth's extremest limit; this sacrifice of ours is the world's center.

The Stallion's seed prolific is the Soma; this Brahman highest heaven where speech abideth.

What thing I truly am I know not clearly; mysterious, fettered in my mind I wander.

When the first-born of holly Law approached me, then of this speech I first obtain a portion.

(Griffith, 2001, p. 107)

This mantric language magnifies mystical horizon. Transcending the space-time dimension of phenomenal reality, these verses give the speech a pattern of eternity by integrating the speech with Brahman, the absolute reality that the Vedic literature proclaims. The verses also express the transcendent reality with the power of imagery language because it is the way to expose the cultural dimension of the society. Whorfian hypothesis also proclaims that culture determines the theory of linguistic relativity. The Vedic literature connects the word with divinity; the power of language is not only to name the objects, rather the language becomes the way to make a quest of absolute reality. Whorf (1956) also says that "speech is the best show man puts on. It is his own "act" on the stage of evolution, in which he comes before the cosmic back drop and really "does his stuff"" (p. 249). The verses above also show the stages of evolution. With the power of speech, one attains the first law i.e. the way of evolution. The Vedic literature is mystical because of its cultural pattern of establishing the cosmic integration. It is only the language which becomes the path for the affinity toward source of Real Thought - the cosmic spirit that the above verses postulate as the Brahman. Speech remains where the Brahman dwells. In this way, the Vedic literature establishes the Brahman as the source of cosmic consciousness. One of the great mantras from Aitteriya Upanishad proclaims: "All this is directed by consciousness, grounded in consciousness; the world is directed by consciousness; the consciousness is its basis, the consciousness is Brahman!" (Deussen, 2010, p. 19). The concept that language shapes our mind and thought becomes a trifling subject in this mantra from the Upanishad. The power of language is established in such a way that it becomes the source of entire consciousness from which the whole universe is guided. Vygotsky also supports the transcendental dimension of the language when he says, "thought is not merely expressed in word; it comes into existence through them" (as cited in Tomasello, 2003, p. 54). Here, language does not simply shape thoughts, but gives existence to them. The above mantric verses from Rig Veda also exactly express the same notion.

The Vedic literature establishes the unity among man, God and nature. The unity is possible only with the power of language. Only the understanding of the true word establishes a worthy communion which can only bring cosmic order and harmony. This is the culture of the people who lived in the entire plain of Ganges and spoke Sanskrit language. In this context, Sapir and Whorf are not only intensified here, but also mystified in these mantric verses from the Rig Veda, book 1, hymn 164, Verse 39 and 45:

Upon what syllable of holy praise - song as twere their highest heaven, the Gods repose them,-

Who knows not this, what will he do with praise-song? But they who know it well sit here assembled.

Speech hath been measured out in four divisions, the Brahmans, who have understanding know them. Three kept in closed concealment cause no motion; of speech, men speak only the fourth division.

(Griffith, 2001, p. 107).

The verses proclaim that only in the word dwells the Gods. The language becomes divine here. It goes even beyond the frontiers of earthly existence. To know the power of Veda's eternal syllable is the way towards the ultimate reality. Only the last quarter is sufficient for human to think and dissect the nature. Other three divisions remain in the domain of cosmic reality. What a powerful and mystical nature of language that the above verses open! Because of this reason, 
the Vedic culture and literature is yogic, a way of binding this world of manifestation to the cosmic transcendent world. It is only through the power of language. Whorf (1956) clarifies this language and transcendental thought dimension:

The idea, entirely unfamiliar to the modern world, that nature and language are inwardly akin, was for ages well known to various high cultures whose historical continuity on the earth has been enormously longer than that of Western European culture. In India, one aspect of it in has been the idea of MANTRAM and of a MANTRIC ART. . . In the high culture, it may have a different, a very intellectual meaning, dealing with inner affinity of language and cosmic order. At a still higher level, it becomes "Mantra Yoga." Therein the mantram becomes a manifold of conscious pattern, contrived to assist into consciousness into the noumenal pattern world-where upon it is "in the driver's seat." (p. 249)

How wonderfully Whorf justifies the mantric and Yogic dimension of language that the Vedic literature proclaims. Yoga is an ultimate path that means "practice, spiritual exercise, integration, moderation, method power" (Zaehner, 1982, p. xxi). Mantric dimension is the way to think not only in phenomenal aspect, but also in divine. When the yogic and mantric aspects of language are united they "assist into consciousness into the noumenal pattern world. And they remain in "the driver's seat" to lead this cosmic process ahead. That combination becomes the prime mover, the inner controller of the entire phenomenal existence and proves as the way for realization of truth. This is the inner deep reality of language that the Vedic literature generates. Zimmer (2011) clarifies these ideas as he says, "concepts and words are symbols, just as visions, rituals, and images are; so too are the manners and customs of the daily life. Through all of these a transcendent reality is mirrored" (p.1). Thus, the Vedic language and literature reflects the patterns of daily affairs, rituals, cultural and religious practices related to the lofty idea of divinity. This is the concept of theory of linguistic relativity that Whorf projects. The Vedic literature transcends spatio-temporal dimension of language, and it carries one into the world beyond the space-time reality because of the power of the language that the literature uses. The mantric language gives the mystic thoughts. Thoughts exist here because of language.

The Atharva Veda also talks about language thought relationship. Here too, the word ( $v \bar{a} c)$ stands for the language. With the divine power, the word does not only dissect this worldly phenomenal existence, but also leads to the ultimate reality. The Atharva Veda section IV hymn one on Brahmavidhya (philosophical interpretation of knowledge) beautifully leads not only the relation between language and thought, but the language crosses spatio-temporal dimension. The language conjoins with level of existent and nonexistent. The Atharva Veda says:

The sacred word which was first-born in the East

the Seer revealed from the shining horizon.

He disclosed its varied aspects, high and low,

the womb of both the Existent and Nonexistent.

May the ancestral Queen who dwells among beings

Stride truth towards primordial creation!

I have conveyed to her his shining Sunbird.

Let them offer warm milk to the one

who is thirsty for worship. (Panikkar, 1994, p. 105)

The Vedic Seers view that the word, $v \bar{a} c$, or language remain "the womb of the both the existent and nonexistent." What a lofty explanation! The Whorfian hypothesis which projects that language dissects the nature is qualified here. Language becomes the power and the source of creation. Likewise, it becomes the source of the whole existent and nonexistent. The Whorfian hypothesis talks about the nature's dissections by language in relation to the manifested reality. The above verses attached the language with the power that dwells "among beings". In this way, the dimension of language is enlarged here with which one can attain the mystical insight. Language manifests both the immanent and transcendent aspects of reality. This is the reality about the dynamism of universe because $v \bar{a} c$ only leads to the wordthe essence of primordial creation. The verses expose the primeval reality of evolution. It is only the evolution of the $v \bar{a} c$ (word/language/speech) that leads to the creation of ideas, concepts and languages. This idea is clarified also by biologist Julian Huxley who says: "The evolution of verbal concepts open the door to all further achievements of man's thoughts" (as cited in Chase, 1955, p.vi). The verses from the Atharva Veda also lead to the evolution of verbal concepts prior to the development of human's thoughts. To come to final point, the Whorfian hypothesis of languagethought interconnection has been justified from a higher plane.

Though the Vedas consist of many such lofty concepts, it is even more rewarding to explore the language-thought dimension in Upanishadic lore that wonderfully and aptly disseminates the projection of Whorfian hypothesis.

\section{THE SAPIR-WHORF HYPOTHESIS IN THE UPANISHADIC LORE}

Upanishads consist of the theoretical and philosophical part of the Veda. They interpret the knowledge, symbols and concepts of the esoteric and exoteric knowledge of the Veda. Because of this reason, they are called Vedanta, which is known as the final, theoretical, and systematized philosophical interpretation of the Veda. These texts too magnify, intensify and interpret the language-thought dimensions so systematically and logically, reverberating Sapir-Whorf hypothesis.

It is obvious that the $v \bar{a} c$ in the canon of the Vedic literature encompasses all the total aspects of words, speech, and 
language. The $v \bar{a} c$ conjoins itself with the creation - the creation of the entire universe. Here are some beautiful lines from Tandya Maha Brahmana, one of the Brahmanas related to the Veda:

This, [in the beginning], was only the Lord of the universe. His word was with him. This word was his second. He contemplated. He said; "I will deliver this word so that she will produced and bring into being all this world." (Panikkar, 1994, p. 107)

The Brahmana leads to the point of the creation, the point of evolution of language that shapes and confirms all other aspects of creation. It becomes clear that language as word is the womb of the entire beings. Thus, the language remains as the basic foundation and prime mover of all creations. The Holy Bible also makes the similar projection about the dynamics of the word: "In the beginning was the Word, in the Word was with God, and the Word was God. He was with God in the beginning" (International Bible Society, 1984, John, 1:1, 2). Then the word becomes the source of creation. The word is anthropomorphized here with the power of cosmic creation. Word determines everything.

Sapir-Whorf hypothesis also considers that language thought interaction is co relational. Language shapes and is shaped by thoughts. This interrelationship is perpetual in the process of cognition. This mythical story from Satapatha Brahmana becomes the exemplification of Sapir-Whorf hypothesis:

Now ones there was a dispute between the Mind and Word. "I am excellent," said the Mind, and the Word said, "I am excellent."

The Mind said: "I am certainly better than you, because you do not utter anything that is not previously understood by me. So, as you just imitate what I am doing and simply follow me, I am certainly better than you."

The Word said; "I am certainly better than you, because whatever you know I make it known, I communicate it."

They went to Prajapati, asking for his decision. Prajapati spoke, in favour of the Mind, saying (to the word): "The Mind is certainly better, because you only imitate and follow what the Mind is doing; and he who is imitating and following what another does is undoubtedly inferior." (Panikkar, 1994, p. 108)

This story clarifies the superiority of mind as the source of thoughts over language. The Sanskrit word "manas" is translated as mind here. The discussion between the manas and $v \bar{a} c$ is the discussion between thought and language. These dialogues clearly justify Sapir's speculation about mind's (thought) influence over the language. The Brahmana, while interpreting the Vedic assumptions, here makes the proposition that mind also plays the significant role, while making the communication possible. However, Whorf explains that manas in the Vedic literature is more than the 'mind' of our ordinary English language. He gives somehow a broad sense to manas. Whorf (1956) writes: "The nearest equivalent is probably manas, to which our vague word "mind" hardly does the justice. Manas in a broad sense is a major hierarchical grade in the world- structure- a "manasic plane" as it is indeed explicitly called" (p. 252). The manas of the Brahmana is not simply like the mind of English equivalent. It holds some value of higher level of cosmic phenomena- a level of consciousness.

The Upanishadic lore solves the duality of Mind and Word. The speculation finds its way that only with a joint effort of manas and $v \bar{a} c$, the naming and cognition processes evolve out. The Brihadaranyaka Upanishad explains: "Speech is this world (the earth), Mind is the atmospheric world (the sky) . . . Mind, verily is the father, Speech is the Mother . . . These same are what is known, what is to be known and what is unknown" (Radhakrishnan, 2016, p. 176). This proclamation solves the dichotomy between mind and language. Moreover, it also justifies Whorf's proclamation of manas as "manasic plan". The Upanishadic lore solves the interconnection between the mind-language or thoughtlanguage process. What is known to us can be dissected, but beyond the frontier of space we cannot attain the knowledge. So Munnich and Landau (2003) clarify: "Foundational concepts—such as space—allow us to speak about the world around us and our experience in it, and spatial language must have evolved so that we can do so" (p. 133). Only, our language gives us the thoughts about the world that is within its periphery.

The interconnection between language-thoughts or language-mind process is the main projection of Sapir-Whorf hypothesis. This two way channel can make the world known to us. One is the foundation of the other and vice versa. The following lines from the Aitteriya Upanishad become the rendezvous and the whole gist of language-thoughts relationship of Sapir-Whorf hypothesis:

May my word be firmly established in my mind!

May my mind be firmly established in my word!

O self- manifest one, be manifest to me!

Be for me the cornerstone of Revelation.

May what I have heard not depart from me!

Thus meditating on your wisdom I link nights and days. (Panikkar, 1994. p. 110)

The mind as the source of thought in word, and word as language and mind can only make the revelation of knowledge possible. The detachment does not make the real knowledge; only the one in another and vice versa make the whole process of knowledge and wisdom possible. In this level, the above invocation from the Aittariya Upanishad reflects the echoes of Sapir-Whorf hypothesis about language-thought or language-mind relationship. The basic foundation of Whorfian hypothesis is that language makes the dissection of nature around us. The whole knowledge 
building process is possible with the lenses of language. This lore from Chandogya Upanishad must be the clear explanation and the summations of Whorfian hypothesis:

... speech makes us understand the Vedas and other Vidyas; heaven, earth, air, space, water, fire, gods, men, cattle, birds, herbs, trees, all beasts down to worms, ants; what is right and what is wrong; what is true and what is false; what is good and what is bad; what is pleasing and what is not pleasing; for, if there were no speech, neither right nor wrong could be known, neither the true nor the false, neither the good nor the bad, neither pleasant nor the unpleasant. Speech makes us understand all this. Meditate on speech. (Muller, 2000, p. 116)

Speech and word represent the totality of language in the literature of the Vedic canon. The lines above from the Upanishad remain as the best exemplification and explanation of Whorfian hypothesis. The lenses of language not only dissect the objects and provide the names for objects, but they also make us understand even the thoughts and concepts about the abstract phenomena.

In the decades of fifties, the Sapir-Whorf hypothesis had impact on "pedagogical and literary experiments" (Traugott and Pratt, 1980, p.107). The thought process of students can be magnified and intensified making them aware of different words and morphemes. The more one learns the words, the wider the zenith of the knowledge becomes. In this context, the Upanishad in the above lines gives the foundational ways of the enlargement and magnification of thinking process. Above all, it proclaims to "meditate on speech". The meditation on speech, obviously, magnifies and increases the periphery of knowledge. To conclude, the Upanishadic lore justifies Whorfian hypothesis or Sapir-Whorf hypothesis and its impact on the knowledge building processes.

\section{CONCLUSION}

Whorfian hypothesis or Sapir-Whorf hypothesis brought a paradigmatic shift in the interconnection between language-thought relationships. The thinking process is possible in human communication because of the drive that language gives. Besides, the dissection and understanding about the aspects of nature find value when the language, shaping the thought views the world. Consequently, the expansion of vocabularies obviously widens the horizon of thoughts, and conversely, curbing language use shrinks thought process. Similarly, the literature of the Vedic canon beautifully exposes the same projection of language-thought interrelationship. The literature values the power of language-thought dimensions in such a way that language transcends spatio-temporal aspects, and it even becomes not only a vehicle to drive thoughts, but also the perfect truth and a way to realize the supreme reality. In this way, the literature of Vedic canon qualifies the Sapir-Whorf hypothesis when it views the language as a unifying string to hold together the divine, the worldly, and the natural aspects of language. The language, its meanings, and their co-relations are not arbitrary. Instead, they have some natural connections related to mantric aspects in the Vedic literature that reveal the lofty concept about the total dimensions of language. The entire verses are symbolic so that they need even more detail and insightful analysis of language, where the nature, the divine, and the world find their rest. These foundational aspects, in this way, make the language of Vedic literature mantra. Every word becomes the voice of divinity from where the radiance of consciousness transfuses throughout the entire creations. Thus, the dissection about this phenomenal world is possible. The mythical stories from Brahmanas, and some mantras from the Upanishads exactly have defined the basic tenets of Sapir-Whorf hypothesis as if Sapir and Whorf have explained their hypothesis in the verses from the literature of the Vedic canon. In this way, the language of the Vedic literature has not only projected, exemplified, and reinterpreted the tenets of Sapir-Whorf hypothesis; rather it has enriched, qualified, magnified, and even mystified the dimensions of language and thought to express the ultimate reality.

\section{REFERENCES}

[1] Chase, S. (1956). Foreword. In B. L. Whorf, Language, thought, and reality. Cambridge: The MIT Press, v-x. Website: https: Ilwww.pdfdrive.com(Acessed 12 September 2020).

[2] Cresswell, J. W. (2011). Research design, qualitative, quantitative, and mixed methods approaches. New Delhi: Sage Publications.

[3] Deussen, P. (2010). Sixty upanisads of the vedas (V.W. Bedekar and G.B. Palsule, trans.). Delhi: Motilal Banarsidass. 2 vols.

[4] Frawley, D. (1992). Wisdom of the ancient seers: Mantras of the rig veda. Salt Lake City: Passage Press. Website: https:Ilwww.pdfdrive.com (Accessed 18 September 2020).

[5] Gentner, D. \& Meadow, S. G. (eds.). (2003). Language in mind. Cambridge: The MIT Press. Website: https: Iwww.pdfdrive.com. (Accessed 12 September 2020).

[6] Goldberg, P. (2010). American veda. New York: Three Rivers Press.

[7] Griffith, R. T. H. (trans.). (2001). The rig veda. Website: https:Ilwww.pdfdrive.com (Accessed 16 September 2020)

[8] Hamilton, S. (2007). Indian philosophy: A very short introduction. New Delhi: Oxford University Press.

[9] Hiriyanna, M. (2000). Outlines of Indian philosophy. Delhi: Motilal Banarsidass.

[10] International Bible Society (1984). The holy bible: New version containing the old testament and the new testament. Bangkok: International Bible Society.

[11] Macdonnel, A. A., Oldenberg, H, \& Muller, M. (trans.). (2014). The golden book of the holy veda. Delhi: Vijay Goel.

[12] Muller, M. (trans.). (2000). The thirteen principal upanishads. Hertfordshire: Wordsworth Classics. 
[13] Munnich, E. \& Landau, B. (2003). The effects of spatial language on spatial representation: Setting some boundaries. In D. Gentner. D. \& S. G. Meadow (eds.), Language in mind. Cambridge: The MIT Press, 113-156. Website: https: Ilwww.pdfdrive.com (Accessed 12 September 2020).

[14] Panikkar, R. (ed. \& trans). (1994). The vedic experience mantramanjari. Delhi: Motilal Banarsidass.

[15] Radhakrishnan. S. (ed., \& trans). (2016). The principal upanisads. London: Harper Collins Publishers.

[16] Seuren, P. A. M. (2013). From Whorf to Montague: Exploration in the theory of language. Oxford: oxford University Press. Website: https: Ilwww.pdfdrive.com (Accessed 16 September 2020).

[17] Tomasello, M. (2003). The key is social cognition. In D. Gentner \& S. G. Meadow (eds.), Language in mind. Cambridge: The MIT Press, 47-58. Website: https:Ilwww.pdfdrive.com (Accessed 12 September 2020).

[18] Traugott, E. C, \& Pratt, M. L. (1980). Linguistics for students of literature. New York: Harcourt Brace Jovanovich.

[19] Whorf. B. L. (1956). Language, thought, and reality (J. B. Carroll, ed.). Cambridge: The MIT Press. Website: https: Ilwww.pdfdrive.com (Accessed 12 September 2020).

[20] Zaehner, R. C. (ed., \& trans.). (1982). The hindu scriptures. London: J. M Dent and Sons Ltd.

[21] Zimmer, H. (2011). Philosophies of India (J. Campbell, trans.). Delhi: Motilal Banarsidass.

Sabindra Raj Bhandari, $\mathrm{PhD}$, is a lecturer in English at Tribhuvan University, Nepal. At present, he is teaching at P. N. Campus, Pokhara. His areas of research are philosophy, language, and literature. He has published various research articles in his areas of interest. 